Research Article

\title{
The interaction and mechanism of monoterpenes with tyramine receptor (SoTyrR) of rice weevil (Sitophilus oryzae)
}

\author{
Almira B. Ocampo ${ }^{1} \cdot$ Mac Kevin E. Braza ${ }^{1} \cdot$ Ricky B. Nellas $^{1}$ (D)
}

Received: 15 April 2020 / Accepted: 20 August 2020 / Published online: 31 August 2020

(c) Springer Nature Switzerland AG 2020

\begin{abstract}
Rice weevils (Sitophilus oryzae) are pests that feed on grain products. One strategy employed in the safe pest management is the use of essential oils from plant materials as biopesticide. Monoterpene compounds, present in essential oils, are generally less acutely toxic than other conventional insecticides and are known to possess biopesticide activity against octopaminergic receptors (OAR). Tyramine receptor (TyrR) is a desired biopesticide target due to its absence in vertebrates and its role in insect's physiological and cellular response. In this study, the biochemical basis of monoterpenes and SoTyrR interactions were determined using in silico methods: ensemble docking, 3DQSAR analysis, and toxicity prediction. Ensemble docking results showed that the lead compounds has binding affinity of -4.2 to $-6.8 \mathrm{kcal} / \mathrm{mol}$. Four monoterpene compounds: terpinolene, carvacrol, carene, and pulegone were considered top hits based on their favorable binding affinity. Furthermore, hydrophobic interactions of monoterpenes with residues Asp114, Val404, Lys189, Leu190, Tyr196, Phe397, and Tyr401 stabilized the observed docking poses. Upon consolidation of docking and 3DQSAR results, we functionalized top hit ligands and showed significant increase in the average binding affinity of candidate compounds, ranging from -4.7 to $-8.3 \mathrm{kcal} / \mathrm{mol}$. A carene derivative exhibited the highest binding energy of $-8.3 \mathrm{kcal} /$ mol with a calculated $K_{i}$ of $0.547 \mu \mathrm{M}$ which surpassed the known activators of OAR. The top hit modified ligands were also clear of toxicity risks as predicted by Osiris Property Explorer. This work could provide insights in the development of effective biopesticides for rice weevils that is less toxic than conventional pesticides.
\end{abstract}

Electronic supplementary material The online version of this article (https://doi.org/10.1007/s42452-020-03395-6) contains supplementary material, which is available to authorized users.

Ricky B. Nellas, rbnellas@up.edu.ph| Institute of Chemistry, College of Science, University of the Philippines Diliman, 1101 Quezon City, Philippines. 


\section{Graphic abstract}

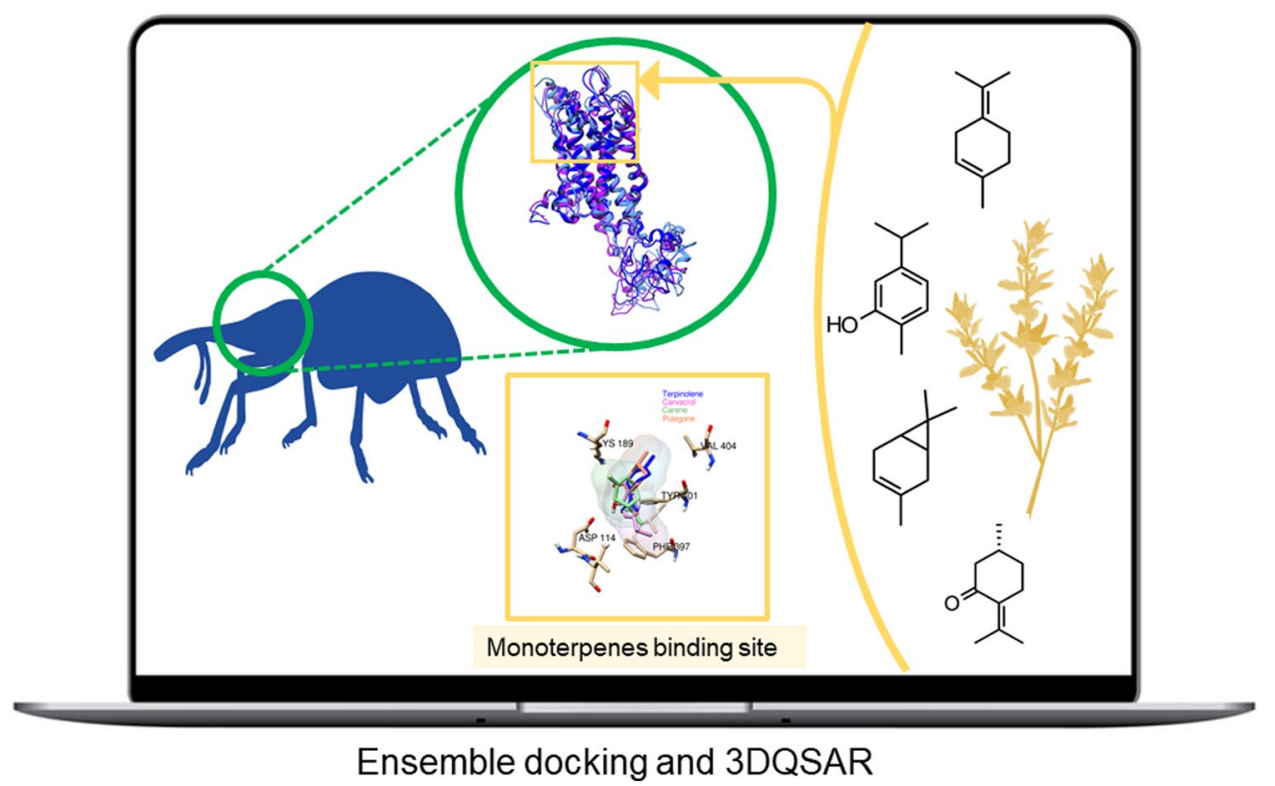

Keywords Tyramine receptors · Monoterpenes · Biopesticide $\cdot$ Rice weevil · Ensemble docking · and 3DQSAR

\section{Introduction}

Rice weevils (Sitophilus oryzae) are one of the most destructive pests of cereal products [1]. They cause significant losses especially at conditions that are favorable to their development [2]. They attack rice, grains, and other crops by feeding and multiplying in stored grain [3]. These creatures attack fields in vast number and destroyed enormous amount of crops in the past [4-7]. One strategy used as safe pest management is the use of essential oils from plant materials as biopesticide [8-10]. The neuromodulatory activity and neurotoxicity of monoterpene compounds were observed to be caused by its ability to interact to protein targets and selectively inhibit specific protein [e.g., acetylcholinesterase (AChE) and octopamine receptors (OAR)] [11]. Despite of their usability as pesticide, the basis of monoterpene interaction with insect receptors remain unknown.

Insect's octopaminergic receptors (OAR) are potential pesticide target of several essential oil products, including monoterpenes [12-16]. Octopamine is the invertebrate counterpart of norepinephrine in vertebrates that functions as neurotransmitter, neuromodulator, and neurohormone $[17,18]$. This compound performs its function when it binds to the rhodopsin-like $G$ protein-coupled receptor (GPCR) located in neuronal cellular membrane in insects [19-22]. GPCRs are known to be involved in extracellular signal sensing. These signals result in some physiological and cellular response which makes GPCRs an interesting target in drug discovery [23].

OARs are grouped into three, namely: (1) $\alpha$-adrenergiclike octopamine receptors (OAR1); (2) $\beta$-adrenergic-like octopamine receptor (OAR2); and (3) tyraminergic receptors (TyrR) [24, 25]. Tyramine has been recently shown to be biologically active independent from octopamine $[26,27]$. Tyramine receptor (TyrR) is associated with many important physiological functions in insect locomotion, reproduction, and pheromone response [28]. Also, the abundance of octopamine receptors in insects and its absence in vertebrates make it an interesting target in the development of bioactives for insects [26]. Recent work suggests that monoterpenes, are highly selective to insects because the primary target, octopamine receptor, is a non-mammalian target [29]. Monoterpenes are widely distributed in plant essential oils. These secondary metabolites are generally less toxic than the other natural and conventional insecticides [30,31]. It is suggested that the repellent activity of several monoterpene compounds depends on the positioning of functional groups and the molecular configuration rather than the volatility and molecular size [32]. Enan and coworkers demonstrated that eugenol, $\alpha$-terpineol, and several other monoterpenoids bound to OARs can be either antagonists or agonists based on the in vitro competitive binding assay [15]. In

\section{SN Applied Sciences}


another study by Gross et al. [33] several monoterpenoids were shown to significantly alter the growth rate of yeast cells by interacting with the $\alpha$-adrenergic-like OAR from Periplaneta americana. Furthermore, a recent study demonstrated the positive allosteric modulation of monoterpenes against Drosophila suzukii type 1 tyramine receptor (DsTAR1) [34].

Moreover, the identification of key amino acid residues is important for the pesticide development. Virtual screening techniques have been successfully applied in drug discovery and has also been validated in agrochemical research $[35,36]$. In the absence of crystal structures of protein receptors, computational methods are employed such as homology modeling, molecular docking, and 3D quantitative structure-activity relationships, 3DQSAR analysis to understand interactions between ligands and target receptors [37-39]. Here, the use of ensemble docking and 3 DQSAR provided a general description for interactions between the $S$. oryzae tyramine receptor (SoTyrR) and monoterpenes. Furthermore, target monoterpene compounds were functionalized to improve their interaction while keeping their toxicity low. Understanding the pharmacological features of SoTyrR-monoterpene interaction can provide insight on receptor-specific biopesticides.

\section{Methods}

\subsection{Ensemble docking and ligand functionalization}

In this study, key amino acid residues for SoTyrR-monoterpene binding interaction were determined. Ensemble docking in AutoDock Vina was done to evaluate the molecular basis of monoterpene binding [40]. A total of 100 protein conformations (ensemble) of $S$. oryzae tyramine receptor (SoTyrR) were used as previously done [28]. In the absence of SoTyrR crystal structure, homology modeling of the target protein was generated in the online server I-TASSER $[41,42]$. SoTyrR was embedded in POPC lipid bilayer and an all-atom MD simulations of SoTyrR were performed. Clustered SoTyrR structures from MD trajectories was analyzed using cpptraj [43]. The 3D structures of monoterpene lead compounds were obtained from the ZINC database online [44]. In AutoDock Tools, a grid box of $20 \times 20 \times 20$ points in $x, y$, and $z$-axis direction was used with a grid spacing of 1 A while centering search box in the extracellular loops of the SoTyrR. Ligands' average binding energy were reported in $\mathrm{kcal} / \mathrm{mol}$. AutoDock Tools and Chimera were used to visualize docking results [45, 46]. Ligands were functionalized using MarvinSketch [47].

\subsection{DQSAR analysis and in silico toxicity evaluation}

Both binding affinities and docking poses were used to assess 3DQSAR in Open3D Align [48] and in Open3DQSAR [49]. The van der Waals and electrostatic fields were calculated using the Merck force field [49]. Using the generated text files from the Open3DQSAR step, the calculated molecular fields were visualized using PyMOL [50]. Contour levels for van der Waals and electrostatic interactions isosurface were adjusted to 0.03 and 0.1 , respectively. The Fractional Factorial Design (FFDSEL) were used to generate van der Waals contour plots. Then, plots generated from Uninformative Variable Elimination by Partial Least Squares (UVEPLS) were used to visualize the electrostatic interactions. The generated plots were used as guide for iterative ligand functionalization. The modified structures were redocked to SoTyrR. On the other hand, OSIRIS Property Explorer [51] was used to assess toxicity of monoterpene compounds. To assess the statistical significant difference between functionalized ligands and the top hit, paired- $t$ test was employed. The $t$ value was calculated using the formula: $t_{\text {calculated }}=\bar{d} /\left(s_{d} / \sqrt{n}\right)$ where $\bar{d}$ is the mean difference between the binding energies of the functionalized ligand to the top hit, $s_{d}$ is the standard error of differences, and $n=100$ [52]. From the $t$ value, GraphPad Software was used to compute for the $p$ value [53]. The $p$ value is the probability that the observed difference is random. A very low $p$ value (usually below 0.10 ) means the difference is statistically significant $[54,55]$. (a)

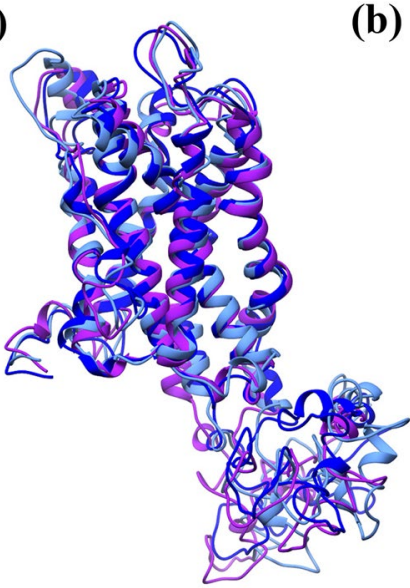

(b)

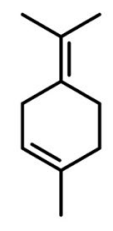

terpinolene

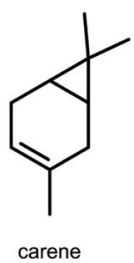<smiles>Cc1ccc(C(C)C)cc1O</smiles>

carvacrol

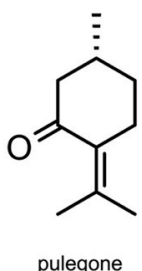

Fig. 1 a Molecular dynamics derived representative structures of Sitophilus oryzae tyramine receptor (SoTyrR); and $\mathbf{b}$ structures of top hit monoterpene ligands 
Table 1 Binding energies of lead monoterpene compounds to target SoTyrR

\begin{tabular}{|c|c|c|}
\hline Ligand & ZINC ID [44] & $\begin{array}{l}\text { Binding } \\
\text { energy (kcal/ } \\
\text { mol) }\end{array}$ \\
\hline Nerol & 12405252 & $-5.31 \pm 0.32$ \\
\hline L-menthol & 1482164 & $-5.59 \pm 0.35$ \\
\hline Citral & 1529208 & $-5.38 \pm 0.30$ \\
\hline cis-geraniol & 1529210 & $-5.38 \pm 0.29$ \\
\hline Linalool & 1529819 & $-5.30 \pm 0.29$ \\
\hline Myrcene & 1530331 & $-5.18 \pm 0.35$ \\
\hline$(+)$-citronellal & 1531600 & $-5.22 \pm 0.29$ \\
\hline (-)-citronellal & 1532245 & $-5.18 \pm 0.29$ \\
\hline (+)-citronellol & 1531601 & $-5.23 \pm 0.30$ \\
\hline (-)-citronellol & 1532246 & $-5.20 \pm 0.29$ \\
\hline Ocimene & 1531618 & $-5.40 \pm 0.33$ \\
\hline$(+)$-sabinene & 1599725 & $-5.49 \pm 0.32$ \\
\hline (-)-sabinene & 1599726 & $-5.56 \pm 0.32$ \\
\hline Camphene & 1673034 & $-5.38 \pm 0.36$ \\
\hline (+)- $\alpha$-thujene & 2035755 & $-5.52 \pm 0.34$ \\
\hline (-)- $\alpha$-thujene & 2035757 & $-5.55 \pm 0.34$ \\
\hline (+)-3-bromocamphor & 507383 & $-5.50 \pm 0.48$ \\
\hline Pulegone & 5735752 & $-5.86 \pm 0.39$ \\
\hline D-limonene & 967513 & $-5.49 \pm 0.32$ \\
\hline (1R)-camphor & 967520 & $-5.35 \pm 0.42$ \\
\hline Carene & 967562 & $-5.68 \pm 0.44$ \\
\hline Carvacrol & 967563 & $-5.88 \pm 0.33$ \\
\hline Eucalyptol & 967566 & $-5.43 \pm 0.36$ \\
\hline (1S)-(-)- $\alpha$-pinene & 967580 & $-5.58 \pm 0.37$ \\
\hline$\beta$-pinene & 967582 & $-5.51 \pm 0.41$ \\
\hline Thymol & 967597 & $-5.75 \pm 0.31$ \\
\hline$(+)$-3-carene & 967794 & $-5.67 \pm 0.34$ \\
\hline (+)-borneol & 968100 & $-5.21 \pm 0.44$ \\
\hline (-)-borneol & 968099 & $-5.27 \pm 0.43$ \\
\hline Terpinolene & 968225 & $-5.76 \pm 0.37$ \\
\hline Camphene & 968230 & $-5.40 \pm 0.37$ \\
\hline p-cymene & 968246 & $-5.64 \pm 0.34$ \\
\hline
\end{tabular}

\section{Results}

\subsection{Ensemble docking}

Representative structures of SoTyrR and top hit ligand structures are reported in Fig. 1. Complete results from ensemble docking of monoterpenes are presented in Table 1 reported as the binding energy $(\mathrm{kcal} / \mathrm{mol}) \pm$ standard deviation (SD) for all 100 protein conformations. Also, the heat map showing the frequency of residues that are closely interacting with the ligands is shown in Fig. 2.

A close interacting residue is determined if the distance between atoms of SoTyrR residues and ligand is $\leq 8 \AA$. . Most frequent interacting residues are defined as those residues that closely-interacted with $\geq 50 \%$ of overall SoTyrR conformations. These residues are reported in Table 2. See SI for a complete list of closely interacting residues and representative protein-ligand diagrams done in Ligplot+ [56]. For instance, terpinolene is found to be interacting with residues found in the space enclosed by $\alpha$-helices structures as displayed in Fig. 3. Top hits were found to share the same binding pocket as shown in Fig. 4. Highest binding affinity of the ligands were recorded from the proximate interactions with Asp114, Lys189, Phe397, Tyr401, and Val404. These residues are the most frequent closely interacting residues that are common to pulegone, carene, carvacrol, and terpinolene.

\subsection{DQSAR analysis}

The docking poses from the ensemble docking were used to assess 3DQSAR of the top hits. Ligands initially chosen for 3DQSAR were the docking poses from all four top hits. This approach gave an $R^{2}$ of 0.0769 at $\mathrm{PC}=5$ and low values of $q^{2}$. Due to the low score correlation and unsatisfactory $q^{2}\left(q^{2}>2\right)$, docking results from the top hits that exhibited the top 10 highest docking score were used instead. This approach gave a higher score correlation of $R^{2}=1$ at $\mathrm{PC}=21$ and acceptable $q^{2}$ values [57]. Figure 5 shows the 3DQSAR model generated.

\subsection{Ligand modification}

Ligands' 3DQSAR analysis is presented in Fig. 5. Using our findings from ensemble docking and 3DQSAR analysis, top hit monoterpenes were functionalized. Most of the top-hit ligands were modified by adding hydrophobic alkyl and hydroxyl groups at different chain lengths and positions. Figure 6 shows functionalized ligands. The subsequent ensemble docking results are summarized in Table 2.

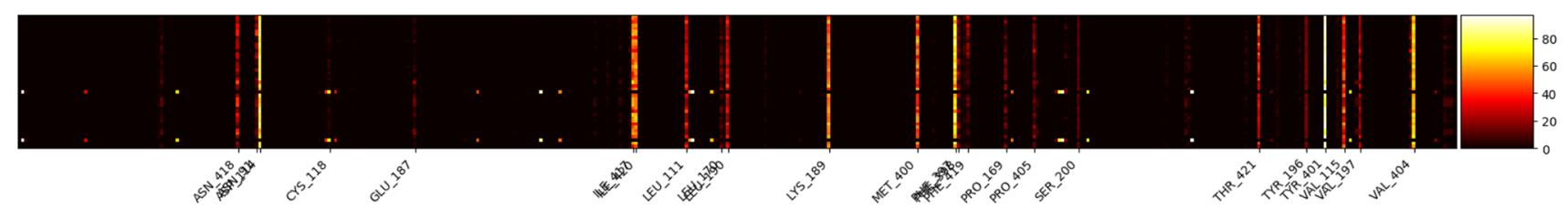

Fig. 2 Heat map showing the frequency of each SoTyrR amino acid residue closely interacting with the docked top-hits ligands. A contact is counted when the distance between ligand and receptor atoms is $\leq 8 \AA$ 
Table 2 SoTyrR closeinteracting residues with the top hit ligands

\begin{tabular}{lll}
\hline Ligand & ZINC ID [44] & Close-interacting residues \\
\hline Terpinolene & 968225 & Asp114, Lys189, Phe397, Tyr401, Val404 \\
Carvacrol & 967563 & Asp114, Val115, Lys189, Phe397, Tyr401, Val404 \\
Carene & 967562 & Asp114, Lys189, Phe397, Met400, Tyr401, Val404, Ile420 \\
Pulegone & 5735752 & Asp114, Val115, Lys189, Phe397, Tyr401, Val404 \\
\hline
\end{tabular}

Fig. 3 Terpinolene binding site and SoTyrR close interacting residues

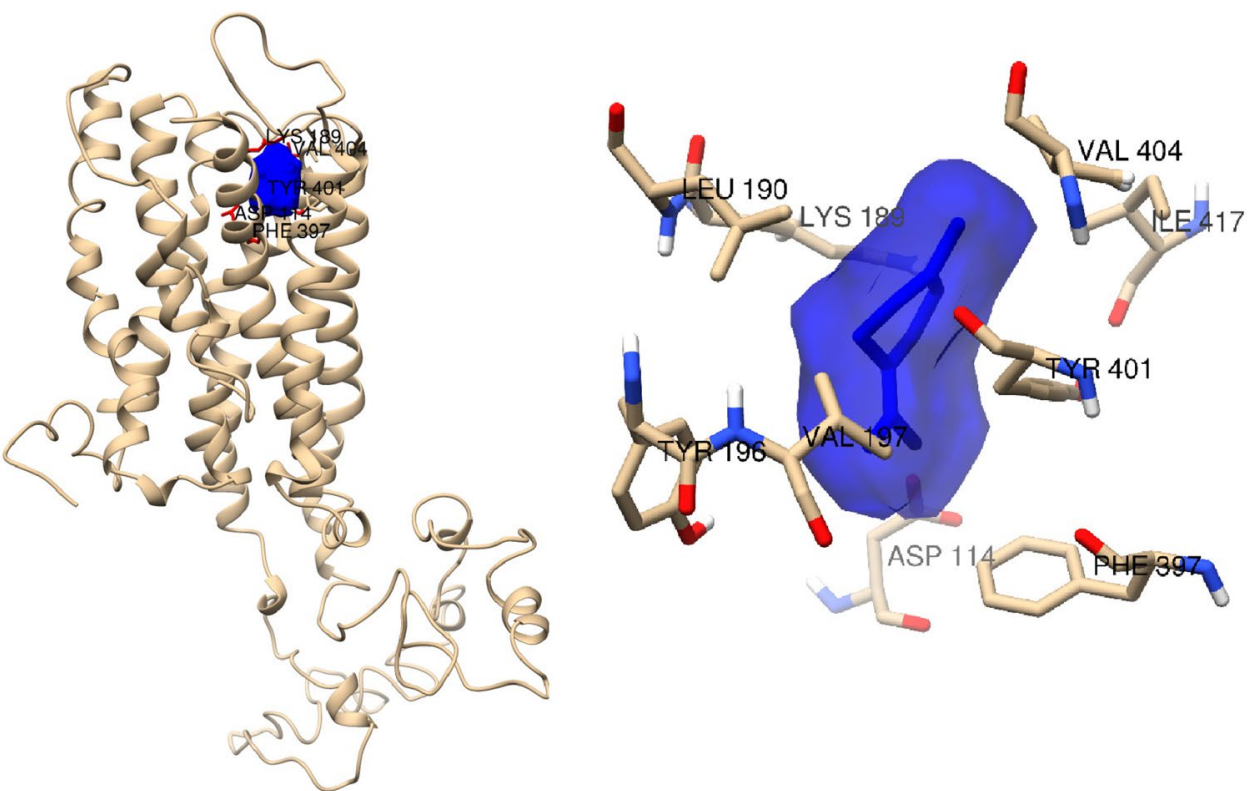

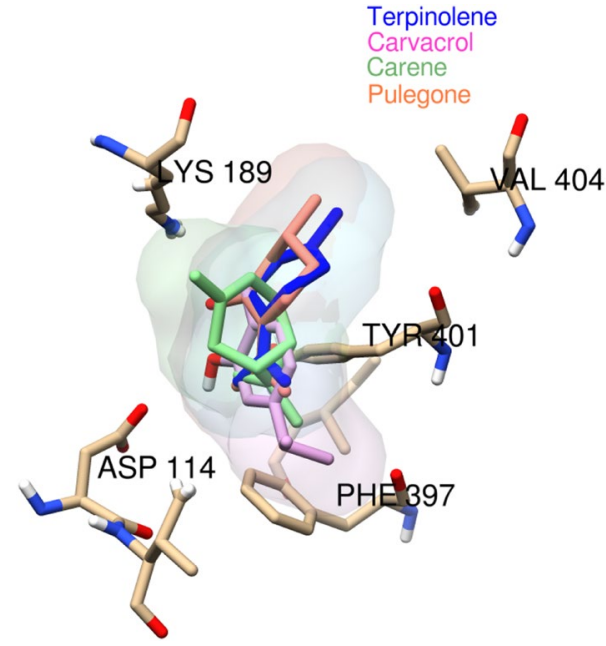

Fig. 4 Top hit ligands occupy similar pose in the SoTyrR binding pocket

Results from ensemble docking of the functionalized ligands are shown in Table 3. Docking scores of each ligand are reported as the average docking score \pm SD for all 100 protein conformations. Modified compounds were also

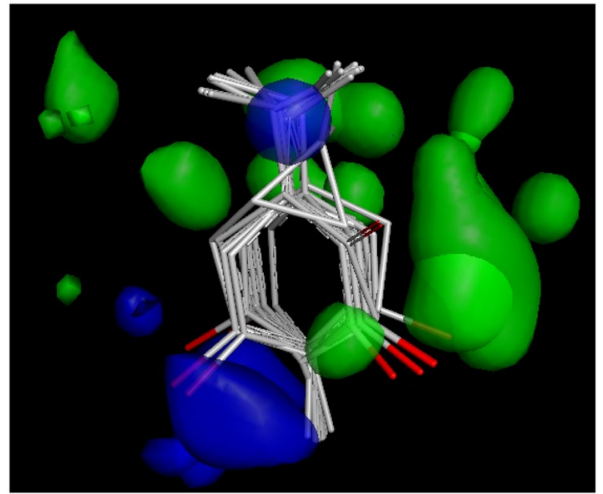

Fig. 5 3DQSAR model for the top 10 of the top hits $\left(R^{2}=1.00\right)$. Green: areas where steric groups should be added; yellow: areas to avoid adding steric groups; blue: sites for positively charged functional groups, red: areas for negatively charged functional groups

subjected to toxicity predictions using Osiris Property Explorer as summarized in Table 4. 
Fig. 6 Chemical structures of functionalized ligands
Terpinolene analogs<smiles>CC1=CCC(=C(C)C)CC1</smiles>

968225<smiles>CC1=CCC(=C(C)C)[C@H](C)C1</smiles>

968225_1<smiles>CCC1CC(C)=CCC1=C(C)C</smiles>

968225_2<smiles>CC[C@H]1CC(C)=C[C@H](C)C1=C(C)C</smiles>

968225_3<smiles>CC[C@H]1C=C(C)C[C@H](CC)C1=C(C)C</smiles>

968225_4<smiles>CCC1C(=C(C)C)[C@@H](CC)C=C(C)C1O</smiles>

968225_5

\section{Carvacrol analogs}<smiles>Cc1ccc(C(C)C)cc1O</smiles>

967563<smiles>Cc1ccc(C(C)(C)C)cc1O</smiles>

967563_1<smiles>Cc1cc(C(C)C)cc(O)c1C</smiles>

967563_2<smiles>Cc1c(O)cc(C(C)C)c(C)c1C</smiles>

967563_3<smiles>CCc1c(O)cc(C(C)C)c(C)c1C</smiles>

967563_4<smiles>CCc1c(C)c(C)c(C(C)C)c(C)c1O</smiles>

967563_5

\section{Carene analogs}<smiles>CC1=CCC2C(C1)C2(C)C</smiles>

967562<smiles>CC(C)C1=CCC2C(C1)C2(C)C</smiles>

967562_1<smiles>CC(C)C1=C[C@@H](C)C2C(C1C)C2(C)C</smiles>

967562<smiles>CCC1(CC)C2C(C)C(C(C)C)=C[C@@H](C)C21</smiles>

967562_3<smiles>CCC1(CC)C2C(C)C(C(C)C)=C(O)[C@H](C)C21</smiles>

967562_4<smiles>CCC1(CC)[C@@]2(C)CC(C(C)C)=C(O)C[C@@]12C</smiles>

967562_5

\section{Pulegone analogs}<smiles>CC(C)=C1CC[C@@H](C)CC1=O</smiles>

5735752<smiles>CCC1C(=C(C)C)C(=O)[C@H](CC)[C@H](C)C1CC</smiles>

5735752_1

5735752_2

\section{Discussion}

Sitophilus oryzae is one of the pests that have caused significant damages to crops like rice and grains. The identification of protein targets of less toxic monoterpenes found in plant essential oils is crucial for formulating species-specific biopesticide. OARs have gained attention as a target for these essential oils. Furthermore, understanding the molecular features of ligand binding to SoTyrR is important to design safer and more effective biopesticide.

Exploring the binding modes of candidate monoterpenes to protein can be done by ensemble docking. This method can give the ligand's binding energy and $3 \mathrm{D}$ pose to a protein conformation. This can address the limitation of crystal structures that represents single<smiles>CCC(CC)=C1C(=O)[C@H](C)[C@H](C)C(C)[C@H]1C</smiles>

5735752_3<smiles>CCC(CC)=C1C(=O)[C@H](CC)[C@H](CC)[C@H]1CC</smiles><smiles>CC[C@H]1C(=O)C(=C(C)C)[C@H](C)C(C)[C@@H]1C</smiles>

5735752_5 conformation of proteins and none of its dynamic behavior [58].

Our results show that a hydrophobic motif induces favorable binding due to its interactions with the hydrophobic fragments in the $\alpha$-helices residues in SoTyrR. There were no $\pi-\pi, \pi$-cation, cation- $\pi$, or t-shaped interactions observed. However, the aromatic residue of Tyr410 is crucial in the binding of terpinolene, carvacrol, carene, and pulegone. Hydrophobic interactions were also found in these 4 monoterpenes with residues Lys189, Val197, and Phe397. In addition, carvacrol has distinct $\mathrm{H}$-bonding interaction with Asp114. These four top hits were also seen to have insecticidal activities to rice weevil. Terpinolene was seen to be effective against rice weevil adults as fumigant [59]. Carvacrol achieved $96.4 \%$ mortality to 
Table 3 Binding energies of modified top hits compounds to SoTyrR

\begin{tabular}{|c|c|c|c|}
\hline Ligand & Binding energy ( $\mathrm{kcal} / \mathrm{mol})$ & Calculated $t$ value & $p$ value \\
\hline 968225_1 & $-5.979 \pm 0.42$ & 3.77 & 0.000 \\
\hline 968225_2 & $-6.174 \pm 0.48$ & 6.73 & 0.000 \\
\hline 968225_3 & $-6.145 \pm 0.47$ & 6.31 & 0.000 \\
\hline 968225_4 & $-6.18 \pm 0.51$ & 6.51 & 0.000 \\
\hline 968225_5 & $-6.264 \pm 0.58$ & 7.20 & 0.000 \\
\hline 967563_1 & $-5.973 \pm 0.39$ & 1.67 & 0.098 \\
\hline 967563_2 & $-6.045 \pm 0.31$ & 3.46 & 0.000 \\
\hline 967563_3 & $-5.942 \pm 0.43$ & 1.07 & 0.287 \\
\hline 967563_4 & $-5.947 \pm 0.43$ & 1.21 & 0.229 \\
\hline 967563_5 & $-5.838 \pm 0.51$ & -0.70 & 0.486 \\
\hline 967562_1 & $-6.177 \pm 0.43$ & 7.88 & 0.000 \\
\hline 967562_2 & $-6.433 \pm 0.51$ & 11.36 & 0.000 \\
\hline 967562_3 & $-6.372 \pm 0.52$ & 10.21 & 0.000 \\
\hline $967562 \_4$ & $-6.358 \pm 0.58$ & 9.46 & 0.000 \\
\hline $967562 \_5$ & $-6.217 \pm 0.57$ & 7.52 & 0.000 \\
\hline 5735752_1 & $-6.188 \pm 0.53$ & 5.31 & 0.000 \\
\hline 5735752_2 & $-6.243 \pm 0.56$ & 5.77 & 0.000 \\
\hline 5735752_3 & $-6.144 \pm 0.54$ & 4.51 & 0.000 \\
\hline 5735752_4 & $-6.223 \pm 0.65$ & 5.05 & 0.000 \\
\hline 5735752_5 & $-6.322 \pm 0.51$ & 7.60 & 0.000 \\
\hline
\end{tabular}

Table 4 Results from toxicity prediction using Osiris Property Explorer

\begin{tabular}{|c|l|l|l|l|}
\hline Ligand & Mutagenic & Tumorigenic & Irritant & $\begin{array}{l}\text { Reproductive } \\
\text { effective }\end{array}$ \\
\hline $968225 \_1$ & & & & \\
\hline $968225 \_2$ & & & & \\
\hline $968225 \_3$ & & & & \\
\hline $968225 \_4$ & & & & \\
\hline $968225 \_5$ & & & & \\
\hline $967563 \_1$ & & & & \\
\hline $967563 \_2$ & & & & \\
\hline $967563 \_3$ & & & & \\
\hline $967563 \_4$ & & & & \\
\hline $967563 \_5$ & & & & \\
\hline $967562 \_1$ & & & & \\
\hline $967562 \_2$ & & & & \\
\hline $967562 \_3$ & & & & \\
\hline $967562 \_4$ & & & & \\
\hline $967562 \_5$ & & & & \\
\hline $5735752-1$ & & & & \\
\hline $5735752 \_2$ & & & & \\
\hline $5735752 \_3$ & & & & \\
\hline $5735752 \_4$ & & & \\
\hline $5735752 \_5$ & & & & \\
\hline
\end{tabular}

(Red: toxicity risk is highly present; orange: toxicity risk is moderately present; green: toxicity risk is not present)

rice weevils when used as fumigant at $46.2 \mathrm{mg} / \mathrm{L}$ air for $96 \mathrm{~h}$ [60]. Carene is seen as a major constituent of Pinus longifolia oil that effectively reduced the population of rice weevils in stored grain [61]. Pulegone at $50 \mathrm{mg} / \mathrm{mL}$ air also caused $100 \%$ mortality to rice weevils tested [62]. Terpinolene, carvacrol, carene, and pulegone were also seen to have repellent potentials to other stored grain insects [62-65].

Based on these key features, the 3DQSAR model confirmed the docking results that most of the interactions were attributed to hydrophobicity. It also showed that the carboxyl group of Asp114 acts as the hydrogen bond donor. The model suggests that the similarity between the top hits' activity were mostly due to their hydrophobic motifs.

Furthermore, ligand functionalizations were based on the combined information from docking and 3DQSAR analyses. Since both analyses suggested that the interaction is mostly hydrophobic in nature, different hydrophobic groups were added in different positions.

The majority of the observed binding affinity of the functionalized ligands were improved. The highest binding affinity was $-8.3 \mathrm{kcal} / \mathrm{mol}$ recorded from ligand 967562 _5 compared to the base top hit molecule $(-6.8 \mathrm{kcal} / \mathrm{mol})$. The carene analog ligand $967562 \_5$ is bound in the same binding pocket as its base molecule. Its improved binding affinity is due to the interaction of the added hydrophobic functional groups to Phe397 and Leu190 and the interaction of the added hydroxyl group to Asp114.

The binding site of tyramine is found in the core of hydrophobic transmembrane bundles. This hydrophobic region putatively form the transmembrane domains of $G$ protein-coupled receptors that mediate signal transduction via an intracellular heterotrimeric $G$ protein. This makes highly hydrophobic ligand binding as one of the most common features due to the nature of the transmembrane helices bundle [28].

The inhibition constant, $K_{i}$, was calculated using the equation $K_{i}=\exp \left[\Delta G R^{-1} T^{-1}\right]$ where $\Delta G$ is the binding energy in $\mathrm{kcal} / \mathrm{mol}, \mathrm{R}$ is equal to $1.9187 \mathrm{cal} / \mathrm{mol} \mathrm{K}$ and $T$ is the temperature equal to $300 \mathrm{~K}$. There is an inverse relationship between the binding affinity and inhibition constant where the higher the binding affinity, the lower is the concentration requirement to inhibit SoTyrR [12]. The calculated $K_{i}$ for ligand $967562 \_5$ is $0.547 \mu \mathrm{M}$ which surpassed the known activators of octopaminergic receptors tyramine and amitraz which has $K_{i}$ of $85.4 \mu \mathrm{M}$ and $1.59 \mu \mathrm{M}$, respectively [28].

Upon subjecting the modified ligands to toxicity test using Osiris Property Explorer, it was seen that majority of the top modified ligands are safe for humans. Ligand 967562_5 exhibited no risks of toxicity. These results support the non-toxic nature of monoterpenes and their analogs in general. Despite these findings, careful examinations should still be necessary as some functionalized monoterpenes appear to be highly toxic. 


\section{Summary}

Tyramine receptors (TyrR) are important in an insect's regulation of physiological functions. Here, an attempt in understanding the key binding features in SoTyrRmonoterpene binding was done using ensemble docking and $3 D Q S A R$. Findings from ensemble docking suggest that binding interactions are mostly hydrophobic and are mediated by residues Asp114, Lys189, Leu190, Tyr196, Phe397, Val404, and Tyr401. This was confirmed through 3DQSAR analysis of the top hit docking poses. This work also suggests the carene analog (ligand 967562_5) is a potential inhibitor of SoTyrR with $K_{i}=0.547 \mu \mathrm{M}$. It was observed that adding hydrophobic alkyl groups and hydrogen bond acceptor to carene can improve the binding affinity of this compound to SoTyrR. This computational approach could aid in further understanding of the mechanisms and the effectivity of monoterpenes as safe biopesticide for S. oryzae and related pest insects.

Acknowledgements A.B.O. would like to acknowledge the Department of Science and Technology Science Education Institute for her scholarship. Computing resources are provided by Department of Science and Technology-Advanced Science and Technology Institute CoARE Facility and the UP Diliman College of Science Computational Science Research Center (CSRC). This study was funded by the Department of Agriculture-BIOTECH Program (Grant: DABIOTECH - R1605) and the University of the Philippines Office of the Vice President for Academic Affairs-Emerging Interdisciplinary Research (EIDR) Program (Grant: EIDR-C06-020.4).

Author contributions R.B.N. designed the experiment. M.K.E.B ran MD simulations and homology modeling. A.B.O. and M.K.E.B performed ensemble docking and analyses. A.B.O. did 3DQSAR analyses and toxicity prediction. All authors reviewed the results and wrote the manuscript.

Data availability The data that support the findings of this study are available from the corresponding author upon reasonable request.

\section{Compliance with ethical standards}

Conflict of interest The authors declare that they have no conflict of interest.

\section{References}

1. Daglish G, Eelkema M, Harrison L (1996) Control of Sitophilus oryzae (L.) (Coleoptera: Curculionidae) in paddy rice using chlorpyrifos-methyl or fenitrothion in combination with several other protectants. J Stored Products Res 32(3):247

2. Batta Y (2004) Control of rice weevil (Sitophilus oryzae L., Coleoptera: Curculionidae) with various formulations of Metarhizium anisopliae. Crop Protect 23(2):103

3. Boniecki P, Piekarska-Boniecka H, Świerczyński K, Koszela K, Zaborowicz M, Przybył J (2014) Detection of the granary weevil based on X-ray images of damaged wheat kernels. J Stored Products Res 56:38

4. Irabagon T (1959) Rice weevil damage to stored corn. J Econ Entomol 52(6):1130

5. Agrawal R, Singh KN, Srivastava PK, Varma BK (1979) Assessment of storage losses in wheat and different refractions in periodic arrivals in the mandis of Haryana. Bull Grain Technol 17(3):202-208

6. Sinha RN, Watters FL (1985) Insect pests of flour mills, grain elevators, and feed mills and their control. Canada Government Publishing Centre, Ottawa, pp 197-200

7. La Hue DW (1958) Treatments for the protection of stored southern-grown corn from rice Weevil attack: exploratory tests. 272 (Marketing Research Division, Agricultural Marketing Service, US Department of Agriculture, 1958)

8. Tripathi AK, Upadhyay S, Bhuiyan M, Bhattacharya P (2009) A review on prospects of essential oils as biopesticide in insectpest management. J Pharmacogn Phytother 1(5):52

9. Mossa ATH (2016) Green pesticides: essential oils as biopesticides in insect-pest management. J Environ Sci Technol 9(5):354

10. Chaubey $\mathrm{M}$ et al (2011) Fumigant toxicity of essential oils against rice weevil Sitophilus oryzae L. (Coleoptera: Curculionidae). J Biol Sci 11(6):411

11. Casida JE, Durkin KA (2013) Neuroactive insecticides: targets, selectivity, resistance, and secondary effects. Annu Rev Entomol 58:99

12. Dacanay F, Ladra M, Junio H, Nellas R (2017) Molecular affinity of mabolo extracts to an octopamine receptor of a fruit fly. Molecules 22(10):1677

13. Gross AD, Kimber MJ, Day TA, Ribeiro P, Coats JR (2014) Investigating the effect of plant essential oils against the American cockroach octopamine receptor ( $\mathrm{Pa}$ oa1) expressed in yeast. Biopesticides: State of the Art and Future Opportunities. American Chemical Society, Washington, DC, pp 113-130

14. Kostyukovsky M, Rafaeli A, Gileadi C, Demchenko N, Shaaya E (2002) Activation of octopaminergic receptors by essential oil constituents isolated from aromatic plants: possible mode of action against insect pests. Pest Manag Sci Former Pestic Sci 58(11):1101

15. Enan E (2001) Insecticidal activity of essential oils: octopaminergic sites of action. Comp Biochem Physiol Part C Toxicol Pharmacol 130(3):325

16. Price MS, David N, Berry (2006) Comparison of effects of octopamine and insecticidal essential oils on activity in the nerve cord, foregut and dorsal unpaired median neurons of cockroaches. J Insect Physiol 52(3:309

17. Orchard I (1982) Octopamine in insects: neurotransmitter, neurohormone, and neuromodulator. Can J Zool 60(4):659

18. Ohta $\mathrm{H}$, Ozoe $Y$ (2014) Molecular signalling, pharmacology, and physiology of octopamine and tyramine receptors as potential insect pest control targets. Adv Insect Physiol 46:73-166

19. Saudou F, Amlaiky N, Plassat J, Borrelli E, Hen R (1990) Cloning and characterization of a Drosophila tyramine receptor. EMBO J 9(11):3611

20. Strader CD, Fong TM, Graziano MP, Tota MR (1995) The family of G-protein-coupled receptors. FASEB J 9(9):745

21. Valdenaire O, Vernier $P$ (1997) G protein coupled receptors as modules of interacting proteins: a family meeting. Prog Drug Res 49:123-158

22. Blenau W, Baumann A (2001) Molecular and pharmacological properties of insect biogenic amine receptors: lessons from Drosophila melanogaster and Apis mellifera. Arch Insect Biochem Physiol Publ Collab Entomol Soc Am 48(1):13

23. Axelrod J, Saavedra JM (1977) Octopamine. Nature 265(5594):501 
24. Evans PD, Maqueira B (2005) Insect octopamine receptors: a new classification scheme based on studies of cloned Drosophila G-protein coupled receptors. Invertebr Neurosci 5(3):111

25. Wu SF, Jv XM, Li J, Xu GJ, Cai XY, Gao CF (2017) Pharmacological characterisation and functional roles for egg-laying of a $\beta$ -adrenergic-like octopamine receptor in the brown planthopper Nilaparvata lugens. Insect Biochem Mol Biol 87:55

26. Farooqui $\mathrm{T}$ (2012) Review of octopamine in insect nervous systems. Open Access Insect Physiol 4:1

27. Roeder T, Seifert M, Kähler C, Gewecke M (2003) Tyramine and octopamine: antagonistic modulators of behavior and metabolism. Arch Insect Biochem Physiol Publ Collab Entomol Soc Am 54(1):1

28. Mac Kevin EB, Gazmen JDN, Eizadora TY, Nellas RB (2019) Ligandinduced conformational Dynamics of A tyramine Receptor from Sitophilus oryzae. Sci Rep 9(1):1

29. Roeder T (1992) A new octopamine receptor class in locust nervous tissue, the octopamine 3 (OA3) receptor. Life Sci 50(1):21

30. Rice PJ, Coats JR (1994) Insecticidal properties of several monoterpenoids to the house fly (Diptera: Muscidae), red flour beetle (Coleoptera: Tenebrionidae), and southern corn rootworm (Coleoptera: Chrysomelidae). J Econ Entomol 87(5):1172

31. Tsao R, Lee S, Rice PJ, Jensen C, Coats JR (1995) Monoterpenoids and their synthetic derivatives as leads for new insect-control agents. ACS Publications, Washington, DC

32. Inazuka S (1983) Monoterpenoids as repellents against the German cockroach (Blattella germanica L.). J Pestic Sci 8(3):293

33. Gross AD, Kimber MJ, Day TA, Ribeiro P, Coats JR (2013) Quantitative Structure-Activity Relationships (QSARs) of monoterpenoids at an expressed American cockroach octopamine receptor. Pest Management with Natural Products. ACS Symposium Series, American Chemical Society, pp 97-110

34. Finetti L, Ferrari F, Caló G, Cassanelli S, De Bastiani M, Civolani S, Bernacchia G (2020) Modulation of Drosophila suzukii type 1 tyramine receptor (DsTAR1) by monoterpenes: a potential new target for next generation biopesticides. Pestic Biochem Physiol 165:104549

35. Lamberth C, Jeanmart S, Luksch T, Plant A (2013) Current challenges and trends in the discovery of agrochemicals. Science 341(6147):742

36. López-Ramos M, Perruccio F (2010) HPPD: Ligand-and targetbased virtual screening on a herbicide target. J Chem Inf Model 50(5):801

37. Bordás B, Kõmíves T, Lopata A (2003) Ligand-based computeraided pesticide design. A review of applications of the CoMFA and CoMSIA methodologies. Pest Manag Sci 59(4):393

38. Jones RT, Bakker SE, Stone D, Shuttleworth SN, Boundy S, McCart C, Daborn PJ, ffrench-Constant RH, Elsen JMVD (2010) Homology modelling of Drosophila cytochrome P450 enzymes associated with insecticide resistance. Pest Manag Sci 66:1106

39. O'Reilly AO, Khambay BP, Williamson MS, Field LM, Wallace B, Davies TE (2006) Modelling insecticide-binding sites in the voltage-gated sodium channel. Biochem J 396(2):255

40. Trott O, Olson AJ (2010) AutoDock Vina: improving the speed and accuracy of docking with a new scoring function, efficient optimization, and multithreading. J Comput Chem 31(2):455

41. Zhang Y (2008) I-TASSER server for protein 3D structure prediction. BMC Bioinform 9(1):40

42. Yang J, Yan R, Roy A, Xu D, Poisson J, Zhang Y (2015) The I-TASSER Suite: protein structure and function prediction. Nat Methods 12(1):7

43. Roe DR, Cheatham TE III (2013) PTRAJ and CPPTRAJ: software for processing and analysis of molecular dynamics trajectory data. J Chem Theory Comput 9(7):3084

44. Irwin JJ, Sterling T, Mysinger MM, Bolstad ES, Coleman RG (2012) ZINC: a free tool to discover chemistry for biology. J Chem Inf Model 52(7):1757
45. Forli S, Huey R, Pique ME, Sanner MF, Goodsell DS, Olson AJ (2016) Computational protein-ligand docking and virtual drug screening with the AutoDock suite. Nat Protocols 11(5):905

46. Pettersen EF, Goddard TD, Huang CC, Couch GS, Greenblatt DM, Meng EC, Ferrin TE (2004) UCSF Chimera-a visualization system for exploratory research and analysis. J Comput Chem 25(13):1605

47. Csizmadia P (1999) MarvinSketch and MarvinView: molecule applets for the World Wide Web

48. Tosco P, Balle T, Shiri F (2011) Open3DALIGN: an open-source software aimed at unsupervised ligand alignment. J Comput Aided Mol Des 25(8):777

49. Tosco P, Balle T (2011) Open3DQSAR: a new open-source software aimed at high-throughput chemometric analysis of molecular interaction fields. J Mol Model 17(1):201

50. DeLano WL (2002) Pymol

51. Sander T, Freyss J, von Korff M, Reich JR, Rufener C (2009) OSI$\mathrm{RIS}$, an entirely in-house developed drug discovery informatics system. J Chem Inf Model 49(2):232

52. Hsu H, Lachenbruch PA (2005) Encyclopedia of biostatistics, vol 6 (2005)

53. Motulsky H (2008) P value calculator. https://www.graphpad. com/quickcalcs/pvalue1.cfm. Accessed 9 July 2020

54. Gorelik B, Goldblum A (2008) High quality binding modes in docking ligands to proteins. Proteins Struct Funct Bioinform 71(3):1373

55. Menke J, Martinez TR (2004) Using permutations instead of student's t distribution for $p$-values in paired-difference algorithm comparisons. In: 2004 IEEE international joint conference on neural networks (IEEE Cat. No. 04CH37541), vol 2. IEEE, pp $1331-1335$

56. Wallace AC, Laskowski RA, Thornton JM (1995) LIGPLOT: a program to generate schematic diagrams of protein-ligand interactions. Protein Eng Des Sel 8(2):127

57. Cramer R, Wendt $B$ (2007) Pushing the boundaries of 3D-QSAR. J Comput Aided Mol Des 21(1-3):23

58. Amaro RE, Baudry J, Chodera J, Demir Ö, McCammon JA, Miao Y, Smith JC (2018) Ensemble docking in drug discovery. Biophys J 114(10):2271

59. Park I, Lee S, Choi D, Park J, Ahn Y (2003) Insecticidal activities of constituents identified in the essential oil from leaves of Chamaecyparis obtusa against Callosobruchus chinensis (L.) and Sitophilus oryzae (L.). J Stored Products Res 39(4):375

60. Erler $F(2007)$ Fumigant activity of monoterpenoids against the rice weevil, Sitophilus oryzae (L.). IOBC WPRS Bull 30(2):281

61. Singh D, Siddiqui M, Sharma S (1989) Reproduction retardant and fumigant properties in essential oils against rice weevil (Coleoptera: Curculionidae) in stored wheat. J Econ Entomol 82(3):727

62. Lee S, Peterson C, Coats J (2003) Fumigation toxicity of monoterpenoids to several stored product insects. J Stored Products Res 39(1):77

63. Cao J, Guo S, Wang Y, Pang X, Geng Z, Du S (2018) Toxicity and repellency of essential oil from Evodia lenticellata Huang fruits and its major monoterpenes against three stored-product insects. Ecotoxicol Environ Saf 160:342

64. Wahba TF, Mackled MI, Selim S, El-Zemity SR (2018) Toxicity and reproduction inhibitory effects of some monoterpenes against the cowpea weevil Callosobruchus maculatus F.(Coleoptera: Chrysomelidae: Bruchinae). Middle East J Appl Sci 8:1061

65. Wang J, Li Y, Lei C (2009) Evaluation of monoterpenes for the control of Tribolium castaneum (Herbst) and Sitophilus zeamaise Motschulsky. Nat Product Res 23(12):1080

Publisher's Note Springer Nature remains neutral with regard to jurisdictional claims in published maps and institutional affiliations. 